\title{
Cordycepin-enriched Cordyceps militaris induces immunomodulation and tumor growth delay in mouse-derived breast cancer
}

\author{
MIN-HO JEONG ${ }^{1,2}$, CHANG-MIN LEE $^{1}$, SANG-WHA LEE ${ }^{1,2}$, SU-YEONG SEO ${ }^{1,2}$, MIN-JEONG SEO $^{2,3}$, \\ BYOUNG-WON KANG ${ }^{2}$, YONG-KEE JEONG ${ }^{2,3}$, YOO-JIN CHOI ${ }^{4}$, KWANG-MO YANG ${ }^{4}$ and WOL-SOON JO ${ }^{4}$ \\ ${ }^{1}$ Department of Microbiology, Dong-A University College of Medicine; ${ }^{2}$ Medi-Farm Industrialization Research Center and \\ ${ }^{3}$ Department of Biotechnology, Dong-A University, Busan 604-714; ${ }^{4}$ Department of Research Center, \\ Dong Nam Institute of Radiological and Medical Sciences, Busan 619-953, Republic of Korea
}

Received June 18, 2013; Accepted July 17, 2013

DOI: 10.3892/or.2013.2660

\begin{abstract}
Cordyceps militaris (C. militaris) and its main functional component, cordycepin, has been shown to possess a number of pharmacological activities including immunological stimulation and antitumor effects. However, the pharmacological mechanisms of $C$. militaris on tumor immunity underlying its antitumor effect have yet to be elucidated. In the present study, we evaluated the antitumor and immunomodulatory effects of $C$. militaris on FM3A tumor-bearing $\mathrm{C} 3 \mathrm{H} / \mathrm{He}$ mice, comparing wild-type $C$. militaris and cordycepin-enriched C. militaris (JLM 0636). The concentration of cordycepin produced by crossbred JLM 0636 was $7.42 \mathrm{mg} / \mathrm{g}$ dry weight, which was 7-fold higher than that of wild-type $C$. militaris. Dietary administration of $C$. militaris revealed retardation of tumor growth as well as elongation of survival rates of tumorbearing mice. This effect was more pronounced in JLM 0636. There was a cordycepin-dependent decrease in IL-2 and TGF- $\beta$ secretion and an increase in IL-4 secretion without changes in the proliferative responses of concanavalin A-stimulated lymphocytes, which suggested that $C$. militaris feeding might induce changes in the subpopulations of tumor-derived $\mathrm{T}$ lymphocytes. $\mathrm{CD} 4{ }^{+} \mathrm{CD} 25^{+}$cell population was significantly reduced in the total splenocytes from JLM 0636-administered mice, while $\mathrm{CD}^{+} \mathrm{T}$ cell population remained unchanged. FoxP3 $3^{+}$-expressing Treg cells among $\mathrm{CD}^{+}{ }^{+} \mathrm{CD} 25^{+}$population showed a similar pattern. On the contrary, $\mathrm{CD} 8^{+} \mathrm{T}$ cells as well as the IFN- $\gamma$ expressing $\mathrm{CD}^{+} \mathrm{T}$ cells from tumor-bearing mice were significantly upregulated by the administration of
\end{abstract}

Correspondence to: Dr Wol-Soon Jo, Department of Research Center, Dong Nam Institute of Radiological and Medical Sciences, Jwadong-gil 40, Jangan-eup, Gijang-gun, Busan 619-953, Republic of Korea

E-mail: sailorjo@dirams.re.kr

Key words: Cordyceps militaris, cordycepin, Treg cell, cytotoxic T lymphocyte, antitumor immunity, FM3A cell
JLM 0636. These results demonstrated the suppressive role of JLM 0636 on the function of Treg cells contributing to tumor specific IFN- $\gamma$-expressing $\mathrm{CD}^{+} \mathrm{T}$ cell responses in tumorbearing mice, which explained the underlying mechanism of the antitumor immunity of cordycepin. Therefore, cordycepinenriched $C$. militaris is a promising candidate for an adjuvant in cancer immunotherapy.

\section{Introduction}

Cordyceps militaris (C. militaris) also known as the rare Chinese caterpillar fungus has been used in traditional medicine to maintain health and to treat numerous diseases associated with circulatory, respiratory, glandular and metabolic systems. Several studies demonstrated that a variety of chemical constituents in $C$. militaris are involved in these activities, with cordycepin, a nucleoside analog (3'-deoxyadenosine), considered to be one of the most important bioactive components mediating its beneficial effects $(1,2)$. C. militaris has been shown to display anti-inflammatory (3), antidiabetic (4), and anti-infectious activities (5-7) conceivably being related to the immune response. Although it has also been considered to have antitumor activities (8-13), there is still considerable uncertainty about the effect on tumor immunity.

The recent advance in the mechanisms responsible for tumor progression have suggested the possibility of controlling tumor growth through chemotherapy-induced cancer cell destruction as well as by stimulating the antitumor immunity. Tumor-infiltrating lymphocytes (TILs) are seen as a reflection of a tumor-related immune response and are recognized as the principal effectors of the local antitumor immune response (14). During the neoplastic process, however, tumor cells acquire immunotolerance and cause an accumulation of immunosuppressive infiltrates in the tumor microenvironment (15). In our previous study, we evaluated the effect of cordycepin purified from $C$. militaris JLM 0636 strain on the production of cytokines in lipopolysaccharidestimulated mouse splenocytes (16). Th1 cytokines such as IL-12 and IFN- $\gamma$, and Th 2 cytokines such as IL-4 and IL-10, were significantly increased by cordycepin; however, IL-2 was 
rather decreased with time, indicating that cordycepin might induce change in the regulatory subpopulation among $\mathrm{CD}^{+}$ T lymphocytes (Treg cells). Treg cell is one of the most potent and well-studied suppressive phenotypes found in the tumor microenvironment, constitutively expressing high levels of CD25, CTLA-4, GITR, and a transcriptional factor forkhead box P3 (Foxp3) (17-19). They play an important role in immune evasion mechanisms employed by tumors which may differentiate, expand, recruit and activate them and potently abrogate antitumor immunity. Indeed, higher numbers of Treg cells are associated with malignancy progression in various solid tumors (lung, breast and pancreas) as well as hematological malignancies. The increased populations of $\mathrm{CD} 4{ }^{+} \mathrm{CD} 25^{+}$Treg cells appear to correlate with a poorer survival for several types of cancer (20).

In the present study, we demonstrated that $C$. militaris induced the immunomodulatory and antitumor properties controlled by the suppression of Treg cell population, which made peritumoral microenvironment unfavorable to tumors and eventually resulted in growth inhibition of tumor cells. We also showed that these effects were dependent on the cordycepin content in $C$. militaris by comparing wild-type C. militaris and cordycepin-enriched C. militaris JLM 0636 strain.

\section{Materials and methods}

Preparation of $C$. militaris and quantitative analysis of cordycepin. $C$. militaris used in the present study was supplied by Chungwon-Industrial Farm (Gimhae, Korea) which had constructed $C$. militaris JLM 0636 strain by single spore fusion of various strains of $C$. militaris. For the preparation of $C$. militaris contained food, the powder of dried fruiting bodies was replaced with cornstarch $3 \%$ in the basal food (casein $20 \%$, cornstarch $15 \%$, sucrose $44.5 \%$, cellurose $5 \%$, corn oil $10 \%$, AIN-93M-MX mineral mixture 4\%, AIN-93-VX vitamin mixture $1 \%$, choline bitartrate $0.2 \%$ and DL-methionine $0.3 \%$ ). For the preparation of $C$. militaris contained water, the powder of dried fruiting bodies was extracted with distilled deionized water for $3 \mathrm{~h}$ at $121^{\circ} \mathrm{C}$, the insoluble materials were removed by centrifugation at $10,000 \mathrm{~g}$ for $30 \mathrm{~min}$ and filtration with $0.45 \mu \mathrm{m}$ membrane filter, and the resulting water extract was added to the standard water to $1 \%$. Cordycepin content in the water extract was analyzed by high performance liquid chromatography (PerkinElmer 200 Series System; PerkinElmer, Waltham, MA, USA) using a Bridge C18 column (4.6 x $250 \mathrm{~mm}, 3.5 \mathrm{~mm}$; Waters, Taunton, MA, USA) and UV Detector $(260 \mathrm{~nm})$. The mobile phase was $0.01 \mathrm{M}$ phosphate buffer, pH 6.5 and linear gradient with $\mathrm{MeOH}$ : $0-15 \%$ for $10 \mathrm{~min}, 15-10 \%$ for $5 \mathrm{~min}, 10-20 \%$ for $2 \mathrm{~min}$ and $20 \%$ for $12 \mathrm{~min}$. The column oven was kept at $40^{\circ} \mathrm{C}$, and the flow rate was $5 \mathrm{ml} / \mathrm{min}$. The cordycepin content was calculated from the peak area shown in the standard curve of commercial cordycepin (Sigma, St. Louis, MO, USA).

Animal and experimental design. Female $\mathrm{C} 3 \mathrm{H} / \mathrm{He}$ mice, 6 weeks of age, were obtained from Central Laboratory Animal Inc., (Seoul, Korea) and housed at the animal maintenance facility of the Clinical Research Center of Dong-A University Hospital. All animals were maintained in specific pathogen- free conditions according to Good Laboratory Practices OECD guidelines. All animal procedures were performed according to approved protocols (Approval number; DIACUC-09-24) from the Institutional Animal Care and Use Committee (IACUC) of Dong-A University and in accordance with recommendations for the proper use and care of laboratory animals. Animals were allowed free access to basal food and standard water for 2 week before the experiment. Animals were then randomly divided into four experimental groups: normal mice group fed with basal food and standard water (normal), tumor-bearing mice group fed with basal food and standard water (control), tumor-bearing mice group fed with wild-type $C$. militaris contained food and water (CMloC), tumor-bearing mice group fed with $C$. militaris JLM 0636 strain contained food and water (CMhiC). FM3A murine breast cancer cells originated from the mammary gland of the $\mathrm{C} 3 \mathrm{H} / \mathrm{He}$ mouse and cells were cultured in RPMI-1640 medium (Invitrogen, Carlsbad, CA, USA) supplemented with $2 \mathrm{mM}$ L-glutamine, $100 \mathrm{U} / \mathrm{ml}$ penicillin, $100 \mu \mathrm{g} / \mathrm{ml}$ streptomycin, and $10 \%$ heat-inactivated fetal bovine serum (FBS; Invitrogen) at $37^{\circ} \mathrm{C}$ in a humidified $5 \% \mathrm{CO}_{2}$ atmosphere. Cells in logarithmic growth phase ( $2 \times 10^{6}$ cells/50 $\mu \mathrm{l}$ saline) were inoculated subcutaneously on the right flank of female $\mathrm{C} 3 \mathrm{H} / \mathrm{He}$ mice. Mice were monitored daily for signs of toxicity and survival, and tumor volumes were measured twice weekly with a caliper. Tumor volumes were calculated as (width) $)^{2} \mathrm{x}$ length $\mathrm{x} 0.52$. When the tumor-bearing mice were sacrificed at day 30 , upon reaching $>100 \mathrm{~mm}^{3}$ of tumor volume, the spleen was aseptically removed. Single cell suspension was prepared by gently teasing the cells through sterile stainless steel screen and the erythrocytes were lysed at room temperature using $\mathrm{ACK}$ lysis buffer $\left(\mathrm{NH}_{4} \mathrm{C}_{1}, \mathrm{KHCO}_{3}\right.$ and $\mathrm{Na}_{2}$ EDTA). The isolated splenocytes were suspended in complete medium (RPMI-1640 supplemented with 10\% FBS, $50 \mathrm{mM}$ 2-mercaptoethanol, $100 \mathrm{U} / \mathrm{ml}$ penicillin and $100 \mu \mathrm{g} / \mathrm{ml}$ streptomycin) and cultured at $37^{\circ} \mathrm{C}$ in a humidified $5 \% \mathrm{CO}_{2}$ atmosphere.

Cytokine production assay. The isolated splenocytes were cultured with concanavalin A (ConA, $5 \mu \mathrm{g}$ ) for $24 \mathrm{~h}$ at $10^{7}$ cells $/ \mathrm{ml}$ in serum-free RPMI medium containing $200 \mu \mathrm{g} / \mathrm{ml}$ BSA. IL-2, IL-4 and TGF- $\beta$ concentrations were determined in supernatant using enzyme-linked immunosorbent assay kits (ELISA; BD Biosciences Pharmingen, San Jose, CA, USA) according to the manufacturer's instructions.

Lymphocyte proliferation assay. Lymphocyte proliferation was determined by BrdU (5-bromo-2-deoxyuridine) incorporation assay using ConA-stimulated cell suspension at $5 \times 10^{5}$ cells/well in flat-bottom 96 -well microculture plates. The cells were cultured for $48 \mathrm{~h}$ and further incubated for $24 \mathrm{~h}$ in the presence of $10 \mu \mathrm{l}$ of the BrdU solution in RPMI medium (1:100 diluent). The BrdU incorporation was measured by using the Cell Proliferation ELISA BrdU kit (Roche Diagnostics-Applied Science, Mannheim, Germany), following the supplier's specifications.

Lymphocyte subpopulation analysis. Lymphocyte subpopulations among splenocytes were determined by flow cytometric analysis. The freshly prepared splenocytes were washed three times with ice cold PBS-containing 0.1\% FBS and then 

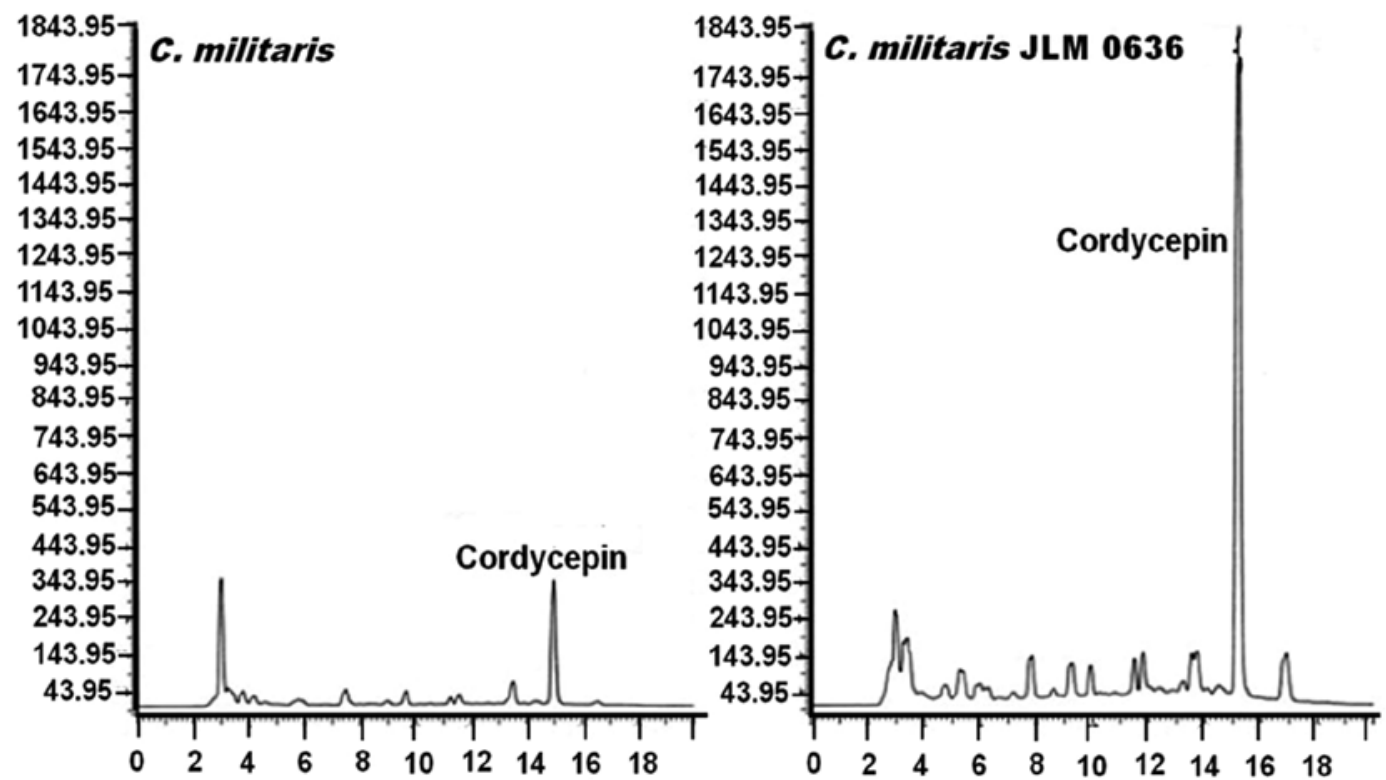

Figure 1. HPLC chromatogram of hot water extracts from wild-type C. militaris and C. militaris JLM 0636 strain.

stained with appropriately diluted labeled rat anti-mouse antibodies [anti-CD4 FITC and anti-CD8 PE (BD Biosciences Pharmingen); anti-CD25 PERCP-Cy5.5 (eBioscience) and isotype controls (BD Biosciences Pharmingen)] at $0.1-0.5 \mu \mathrm{g} / \mathrm{ml}$ for $40 \mathrm{~min}$ on ice. For the identification of intracellular IFN- $\gamma$ expression in $\mathrm{CD}^{+} \mathrm{T}$ cells, the freshly prepared cells were stimulated with PMA (50 ng/ml; Sigma) and ionomycin (500 ng/ml; Sigma) for $2 \mathrm{~h}$ and further incubated with protein transport inhibitor brefeldin A (10 $\mu \mathrm{g} / \mathrm{ml}$; Sigma) for $2 \mathrm{~h}$ to accumulate for intracellular cytokines. At the end of the incubation, $\mathrm{Fc}$ Block (BD Biosciences Pharmingen) was added for $15 \mathrm{~min}$ at $4^{\circ} \mathrm{C}$, and standard surface staining procedures were performed with anti-CD8 PE. The cells were then fixed, permeabilized and stained with anti-IFN- $\gamma$ FITC (BD Biosciences Pharmingen). Following staining, cells were washed and analyzed immediately with an FC500 flow cytometer (BD FACSAria; BD Biosciences). Two color flow cytometric analyses were performed and data represent 50,000 events unless otherwise noted. The phenotype of Treg cells $\left(\mathrm{CD} 4^{+} \mathrm{CD} 25^{+} \mathrm{FoxP} 3^{+}\right)$was evaluated by three-color fluorescence flow cytometric analysis following standard surface staining procedures combined with intracellular FoxP3 staining method. Intracellular detection of FoxP3 was performed by using PE anti-mouse FoxP3 staining buffer set purchased from eBioscience. Briefly, the cells stained with anti-CD4-FITC and anti-CD25-PERCP-Cy5.5 were washed, fixed and permeabilized according to the manufacturer's instructions, and then incubated with PE-conjugated rat anti-mouse FoxP3 $\mathrm{Ab}$ for $40 \mathrm{~min}$ on ice.

Statistical analysis. All statistical analyses were performed using commercially available statistical software (SPSS, Inc., Chicago, IL, USA). Results are expressed as means \pm standard deviation (SD), and numerical data were analyzed by Student's t-test or one-way analysis of variance (ANOVA). For all analyses, a difference was considered statistically significant at $\mathrm{P}<0.05$.

\section{Results}

Induction of immunomodulation by cordycepin-enriched C. militaris. For the determination of cordycepin content, hot water extract was prepared and subjected to HPLC analysis (Fig. 1). The concentration of cordycepin contained in $C$. militaris JLM 0636 strain $(7.42 \mathrm{mg} / \mathrm{g}$ dry weight) was 7-fold higher than that of wild-type $C$. militaris $(1.21 \mathrm{mg} / \mathrm{g}$ dry weight), which was calculated from the peak area shown in the standard curve of commercial cordycepin. To examine whether $C$. militaris could lead modulation of tumor-derived $\mathrm{T}$ cells, ConA-stimulated lymphocyte proliferative response was tested by BrdU incorporation assay. The ConA response of splenocytes from tumor-bearing mice was generally lower than that from normal mice and was not significantly altered by the feeding of $C$. militaris (Fig. 2). Having demonstrated the presence of cytokines for the development of effector T cells and Treg cells, the cultured supernatants of ConA-stimulated lymphocytes were analyzed for the production of IL-2, IL-4 and TGF- $\beta$. Tumor-bearing mice fed with $C$. militaris showed cordycepin-dependent decrease in IL- 2 and TGF- $\beta$ production and increase in IL-4 production (Fig. 2), which indicated that $C$. militaris may induce changes in the subpopulations of tumor-derived $\mathrm{T}$ lymphocytes. Thus, immunofluorescent analysis for cell surface markers using flow cytometric analysis was performed to investigate T lymphocyte subpopulations. The average frequencies of $\mathrm{CD} 4^{+} \mathrm{T}$ cells among total splenocytes from tumor-bearing mice groups were generally lower than the normal mice group and were not significantly altered by the differences in the feeding conditions (data not shown). The frequency of $\mathrm{CD}^{+} \mathrm{T}$ cells from the control tumor-bearing mice group was also decreased compared with the normal mice group; however, $C$. militaris feeding prominently recovered the frequencies of $\mathrm{CD}^{+} \mathrm{T}$ cells particularly in the cordycepin-enriched $C$. militaris JLM 0636 fed group (Fig. 4). 

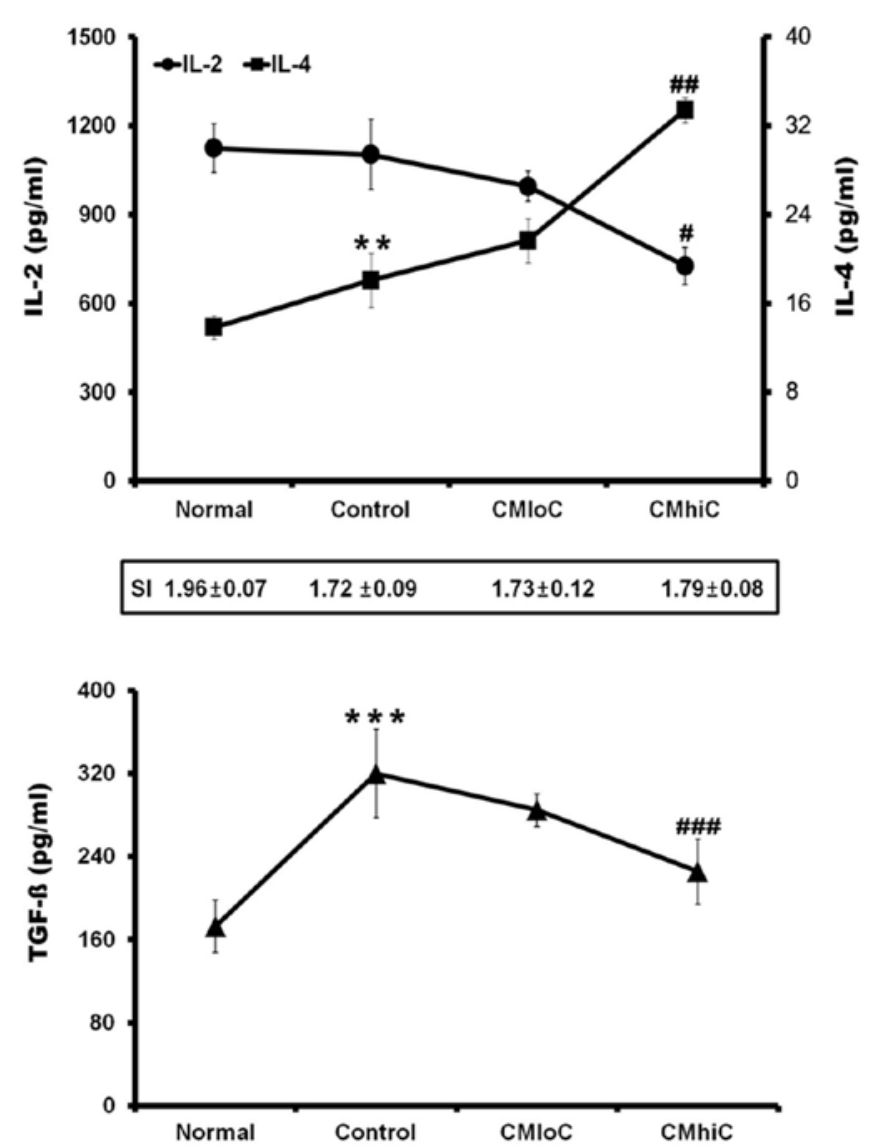

Figure 2. Cordycepin-enriched C. militaris induces modulation of tumorderived $\mathrm{T}$ cells. $\mathrm{C} 3 \mathrm{H} / \mathrm{He}$ female mice were inoculated s.c. with $2 \times 10^{6} \mathrm{FM} 3 \mathrm{~A}$ tumor cells in $50 \mu 1$ saline. Splenocytes were obtained at 30 days after inoculation of tumor cells and cultured with ConA-stimulation $(5 \mu \mathrm{g} / \mathrm{ml})$. The concentrations of IL-2, IL- 4 and TGF- $\beta$ were analyzed in the supernatants which were cultured for $24 \mathrm{~h}$ at $10^{7}$ cells $/ \mathrm{ml}$. Stimulation index (SI) mean ratio of ConA-stimulated/spontaneous proliferation determined by BrdU incorporation assay using cell suspension at $5 \times 10^{5}$ cells/well. Data are presented as means $\pm \mathrm{SD}$ of 5 mice/group. ${ }^{* * * * * * * *} \mathrm{P}<0.05$ as compared with the

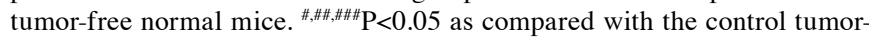
bearing mice.

Suppression of Treg cells by cordycepin-enriched C. militaris. To investigate the effect of $C$. militaris on Treg cell population, $\mathrm{CD} 4{ }^{+} \mathrm{CD} 25^{+}$cell proportions were determined by flow cytometric analysis. Based on the changes in the average frequency of $\mathrm{CD} 4^{+} \mathrm{T}$ cells between the normal and tumor-bearing mice groups, comparison of $\mathrm{CD} 4^{+} \mathrm{CD} 25^{+}$to $\mathrm{CD} 4^{+}$cell ratio was better to discriminate the differences between groups. The higher ratio of the control tumor-bearing mice group compared to the normal mice group was significantly decreased in the cordycepin-enriched C. militaris JLM 0636 fed group (Fig. 3). The expression of a specific Treg cell marker, FoxP3, was further investigated to confirm that the reduced $\mathrm{CD} 4^{+} \mathrm{CD} 25^{+}$ cells were true Treg cells. The proportions of FoxP3 ${ }^{+}$cells among $\mathrm{CD} 4{ }^{+} \mathrm{CD} 25^{+}$cells showed similar but more prominent changes between the experimental groups (Fig. 3). On the other hand, FoxP $3^{+}$cells among $\mathrm{CD} 4{ }^{+} \mathrm{CD} 25$ cells were almost unchanged at minimal level (data not shown).

Enhancement of IFN- $\gamma$-expressing CD8 T cells by cordycepinenriched $C$. militaris. To investigate whether $C$. militaris could

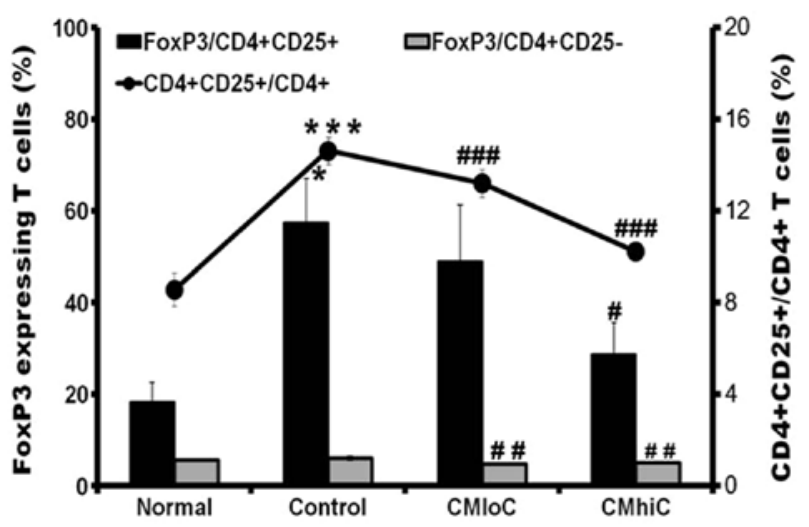

Figure 3. Cordycepin-enriched C. militaris suppresses Treg cells in tumorbearing mice. $\mathrm{C} 3 \mathrm{H} / \mathrm{He}$ female mice were inoculated s.c. with $2 \times 10^{6} \mathrm{FM} 3 \mathrm{~A}$ tumor cells in $50 \mu 1$ saline. Splenocytes were obtained at 30 days after inoculation of tumor cells. The cells were analyzed by flow cytometry for the expressions of CD4, CD25 and intracellular FoxP3 and expressed as percent gated cells of $\mathrm{CD}^{+} \mathrm{CD} 25^{+}$cells among $\mathrm{CD} 4^{+} \mathrm{T}$ cells and FoxP3 expressing cells within $\mathrm{CD} 4{ }^{+} \mathrm{CD} 25^{+}$cells. Data are reported as the means $\pm \mathrm{SD}$ of 5 mice/group. ${ }^{* * * * * * *} \mathrm{P}<0.05$ as compared with the tumor-free normal mice. $\#, \#, \#, \# \# \mathbb{P}<0.05$ as compared with the control tumor-bearing mice.

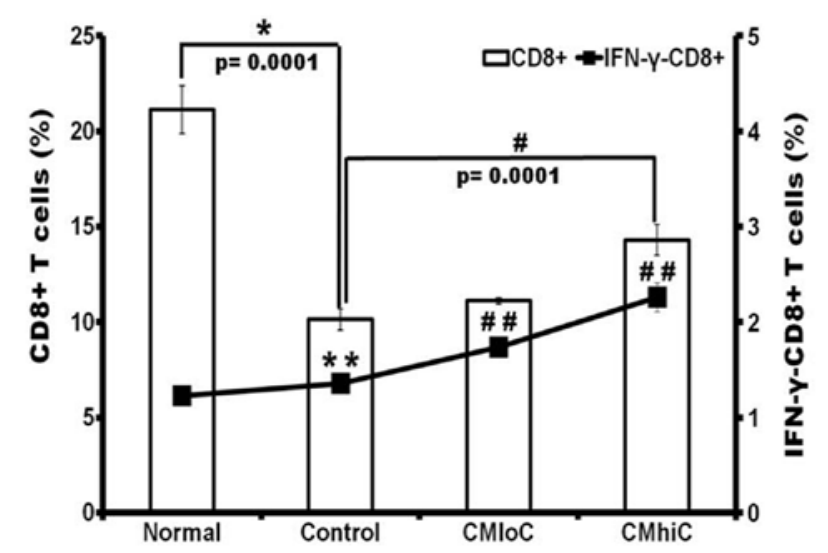

Figure 4. Cordycepin-enriched $C$. militaris enhances IFN- $\gamma$-expressing CD8 $\mathrm{T}$ cells in tumor-bearing mice. $\mathrm{C} 3 \mathrm{H} / \mathrm{He}$ female mice were inoculated s.c. with $2 \times 10^{6} \mathrm{FM} 3 \mathrm{~A}$ tumor cells in $50 \mu 1$ saline. Splenocytes were obtained at 30 days after inoculation of tumor cells. The cells were analyzed by flow cytometry for the expressions of $\mathrm{CD} 8$ and intracellular IFN- $\gamma$ and expressed as percent gated cells of $\mathrm{CD}^{+}$cells and IFN- $\gamma$-expressing $\mathrm{CD}^{+} \mathrm{T}$ cells. Data are reported as the means $\pm \mathrm{SD}$ of 5 mice/group. Student's t-test $\mathrm{P}<0.05$ for tumor-free normal mice vs. control (* and **) and Dunnett's multiple comparison posttest $\mathrm{P}<0.05$ for control vs. CMIoC or CMhiC (\# and \#\#).

lead to enhanced effector T cells involved in antitumor immunity in tumor-bearing mice, IFN- $\gamma$-expressing $\mathrm{CD}^{+} \mathrm{T}$ cells were examined by flow cytometric analysis. The number and percentage of IFN- $\gamma$-expressing $\mathrm{CD} 8^{+} \mathrm{T}$ cells in tumor-bearing mice were significantly increased in the experimental groups fed with $C$. militaris, compared to those in the normal mice (Fig. 4). The degree of increase was much more pronounced in the mice group fed with the $C$. militaris JLM 0636 strain, which was in accordance with the recovery of the frequencies of $\mathrm{CD}^{+} \mathrm{T}$ cells. This result indicates that $C$. militaris enhanced IFN- $\gamma$ secretion and effector T cell function, which may suggest unfavorable microenvironmental change to tumor and induction of effective antitumor immunity. 

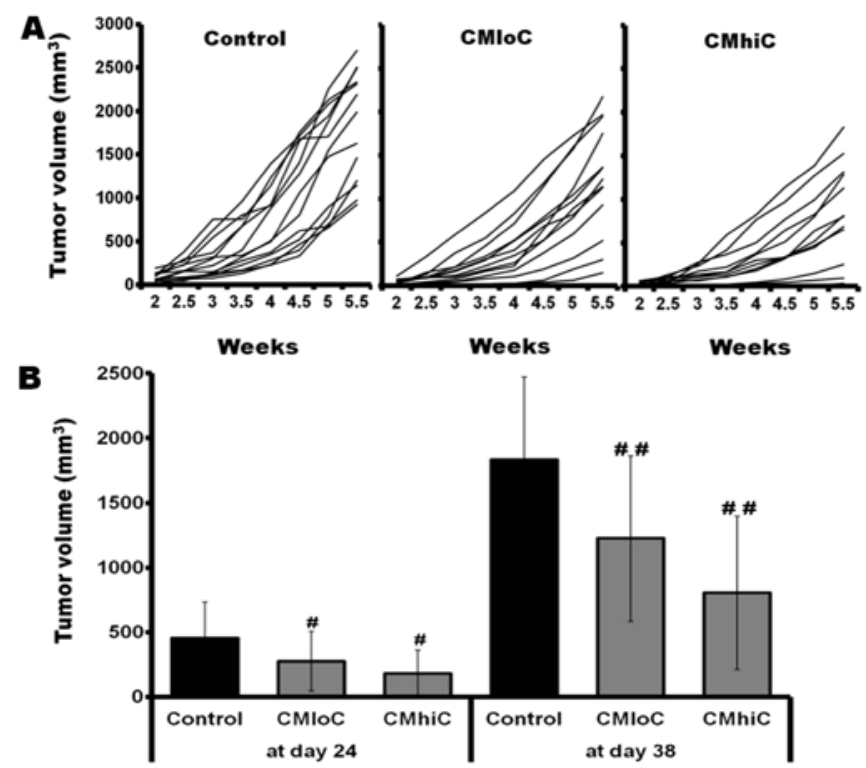

C

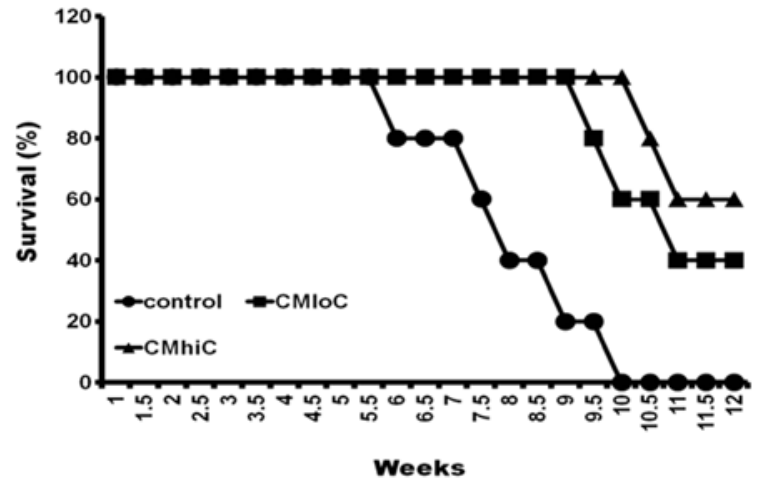

Figure 5. Antitumor activity of C.militaris. $\mathrm{C} 3 \mathrm{H} / \mathrm{He}$ mice of each experimental group were inoculated subcutaneously with FM3A cells $\left(2 \times 10^{6}\right.$ cells $/ 50 \mu 1$ saline) on the right flank. (A) Tumor size was assessed once a week, and data are reported as tumor growth curve of individual mice in the relevant group. (B) Tumor growth delay compared with control was significantly increased by $C$. militaris powder and water extract contained diet at day 38 . Data are reported as the means \pm SD of 5 mice/group. Dunnett's multiple comparison posttest $\mathrm{P}<0.05$ for control vs. CMIoC or CMhiC (\# and \#\#). (C) Survival rate was recorded as the percentage of surviving mice in each experimental group.

Tumor growth delay by cordycepin-enriched C. militaris. To determine the ability of $C$. militaris to induce a protective antitumor activity in vivo, mice were fed systematically with C. militaris powder and water extract contained diet during which mice were challenged subcutaneously with FM3A murine breast cancer cells. When mice were fed with $C$. militaris, tumor formations were delayed and the survival rates were prolonged compared with control mice (Fig. 5). The mice group fed with $C$. militaris JLM 0636 strain showed much slower tumor growth and survived for longer time periods than the mice group fed with wild-type $C$. militaris (Fig. 5). C. militaris at the dose used was not toxic to the animals as we observed no differences in body weight gain, food intake, water consumption and behaviors between experimental groups until visible tumor formation. Although these parameters of tumor-bearing mice were gradually decreased with the lapse of time compared with the normal mice, there were no significant differences between control and $C$. militaris-fed mice (data not shown).

\section{Discussion}

There has been considerable interest in cordycepin as a potential cancer chemotherapeutic agent. Due to the absence of oxygen in the 30 position of its ribose moiety, the incorporation of cordycepin during RNA synthesis results in termination of chain elongation. This activity has been well described in vitro with purified RNA polymerases and poly (A) polymerases from a number of organisms, including yeast and mammals $(21,22)$. However, cordycepin is not a potent cytotoxic compound when compared to other chemotherapeutic drugs, and the chemical compounds including cordycepin contained in C. militaris have been known to mediate unique properties related to the immunity. As tumor growth can be controlled by destroying cancer cells as well as by stimulating antitumor immunity, it is necessary to explore the role of $C$. militaris in immune response underlying antitumor activity. For this purpose, we constructed C. militaris JLM 0636 strain with 7-fold higher cordycepin content than wild-type $C$. militaris and fed each containing food and water to mice inoculated with FM3A tumor cells. The results presented in the present study showed that the feeding of cordycepin-enriched C. militaris JLM 0636 strain for 30 days had a considerable effect on in vivo growth and survival rate of an FM3A breast tumor in $\mathrm{CH} 3 / \mathrm{He}$ mice (Fig. 5), which demonstrated that it may be one of the most appropriate candidate antitumor substances.

The antitumor effect can be explained to the end-result of several interactions involving cytokines and immune cells, provided by the stimulatory or suppressive effects on the antitumor immunity (23). The lack of an effective antitumor immune response in most cancer patients with advanced disease would simply depend on the prevalence of immunosuppressive mechanisms with respect to the immunostimulatory ones. The suppression of the antitumor immune response is mediated by several cytokines, and the various endogenous suppressive factors would exert their inhibitory immune effect through a common end-mechanism, consisting of the generation of a subtype of $\mathrm{T}$ helper lymphocytes (Treg cell), which at present seems to constitute the main mechanism responsible for cancer-related immunosuppressive status (24).

In the present study, ConA-stimulated lymphocyte proliferative response of splenocytes from tumor-bearing mice, which was lower than that of normal mice, was unaltered by the feeding of $C$. militaris (Fig. 2). However, it is noteworthy that IL-2, IL-4 and TGF- $\beta$ secretion of ConA-stimulated lymphocytes from tumor-bearing mice was modulated in a cordycepin-dependent manner by the feeding of $C$. militaris (Fig. 2). C. militaris also induced changes in the subpopulations of tumor-derived $\mathrm{T}$ lymphocytes. The average frequency of $\mathrm{CD} 4^{+} \mathrm{T}$ cell population among total splenocytes from tumorbearing mice, which was lower than that from normal mice, was not significantly altered by the feeding of $C$. militaris. However, $\mathrm{CD} 4{ }^{+} \mathrm{CD} 25^{+}$cell population from the tumor-bearing mice, which was higher than that in the normal mice, exhibited a cordycepin-dependent decrease, and this decreasing trend in the $\mathrm{CD} 4{ }^{+} \mathrm{CD} 25^{+}$cell population became more definite when it was illustrated in terms of the $\mathrm{CD} 4{ }^{+} \mathrm{CD} 25^{+}$to $\mathrm{CD} 4^{+}$ cell ratio (Fig. 3). The regulatory subpopulation among $\mathrm{CD}^{+}$ cells constitutively expressing high levels of CD25 (Treg cells) is one of the most potent and well-studied suppressive 
phenotypes found in the tumor microenvironment. Indeed, IL-2, IL-4 and TGF- $\beta$ are essential for naturally occurring Treg cell homeostasis and activation. Treg cells are refractory to TCR-induced proliferation $(25,26)$ and depend on IL-2 for survival $(27,28)$. The signaling via the high-affinity IL-2R complex, in combination with TCR engagement, is essential for Treg cell proliferation as well as the acquisition of their potent suppressive function (28). IL-2 leads to phosphorylation and activation of STAT5 and, consequently, binding to the FoxP3 promotor, resulting in enhanced FoxP3 expression (29). TGF- $\beta$ induces $C D 4{ }^{+} \mathrm{CD} 25^{+}$T-cell proliferation $(30,31)$ and promotes the differentiation of $\mathrm{CD} 4{ }^{+} \mathrm{CD} 25^{+}$Treg cells as a costimulator of FoxP3 expression (32). By contrast, IL-4 inhibits TGF- $\beta$-induced Foxp3 expression and thus suppresses the new generation of Foxp $3^{+}$Treg cells (33). It may be assumed that $C$. militaris inhibited IL- 2 and TGF- $\beta$ secretion and promoted IL-4 secretion of tumor-derived T lymphocytes, which downregulated $\mathrm{CD} 25^{+}$-expressing CD $4^{+} \mathrm{T}$ cells more sensitively. As the transcriptional factor FoxP3 is crucial in the developmental and functional factors expressed in Treg cells and is regarded as a useful intracellular Treg cell marker, we investigated the expression of FoxP3 to more clearly define Treg cells. FoxP3 was expressed mainly in the $\mathrm{CD} 4{ }^{+} \mathrm{CD} 25^{+}$ cell population and was extensively increased in cells from tumor-bearing mice. Moreover, $\mathrm{CD} 4^{+} \mathrm{CD} 25^{+} \mathrm{FoxP} 3^{+}$cells were decreased significantly after the feeding of $C$. militaris in a cordycepin-dependent manner (Fig. 3).

Tumor-infiltrating lymphocytes are seen as a reflection of a tumor-related immune response and are recognized as the principal effectors of a local antitumor immune response, particularly IFN- $\gamma$-producing $\mathrm{CD}^{+} \mathrm{T}$ cells (cytotoxic T lymphocytes; CTL) which kill tumor cells and impede tumor growth (14). As shown in the results of our present study, the average frequency of $\mathrm{CD}^{+} \mathrm{T}$ cell population among total splenocytes from the tumor-bearing mice, which was lower than that from normal mice, was significantly increased by the feeding of $C$. militaris. The IFN- $\gamma$-producing $\mathrm{CD}^{+} \mathrm{T}$ cell population from tumor-bearing mice also showed a cordycepin-dependent increase (Fig. 4). IFN- $\gamma$ plays a key role in tumor surveillance and immunoediting and block TGF- $\beta$-mediated Treg cell differentiation (34), while Treg cells suppress tumor specific $\mathrm{CD}^{+} \mathrm{T}$ cell cytotoxicity through TGF- $\beta$ signals in vivo (35). Although the exact mechanism of enhanced IFN- $\gamma$ expression in $\mathrm{CD}^{+}$cells by the feeding of $C$. militaris remains unclear, it may be related, in part, to $C$. militaris-induced Treg cell depletion in tumor-bearing mice.

In conclusion, the present study revealed that cordycepinenriched $C$. militaris effectively suppressed the Treg cell population and enhanced IFN- $\gamma$ production of $\mathrm{CD}^{+} \mathrm{T}$ cells in FM3A breast cancer cell-bearing $\mathrm{C} 3 \mathrm{H} / \mathrm{He}$ mice. Furthermore, another advantage of cordycepin-enriched $C$. militaris involves the fact that the $\mathrm{CD}^{+}$cell pool did not decrease, which may include tumor-specific $\mathrm{CD}^{+}$cells involved in antitumor immunity. Based on the results of our present and previous studies, cordycepin-enriched $C$. militaris itself could be applied as an adequate principal therapeutic agent, facilitating the immune system against pre-established cancer and inducing apoptosis of cancer cells. As it is an ideal conditioning strategy to make the peritumoral microenvironment unfavorable to tumor merely by manipulating Treg cells without harming the host tissue, cordycepin-enriched $C$. militaris may be applied as an adequate therapeutic agent against the tumor, facilitating antitumor immunity via Treg cell depletion and CTL enhancement. Furthermore, cordycepin-enriched $C$. militaris-induced antitumor immunity may play a factor via a bystander effect in eradicating chemotherapy or radiotherapy-resistant cancer cells and may synergistically act when treated with dendritic cell vaccine.

\section{Acknowledgements}

This research was supported by the 2013 National R\&D Program through the Dongnam Institute of Radiological and Medical Sciences (DIRAMS) funded by the Ministry of Education, Science and Technology (50493-2013 and 50592-2013) and the Technology Development Program for Agriculture and Forestry (610003-03-1-SB110), Ministry for Food, Agriculture, Forestry and Fisheries, Republic of Korea.

\section{References}

1. Cunningham KG, Manson W, Spring FS and Hutchinson SA: Cordycepin, a metabolic product isolated from cultures of Cordyceps militaris (Linn.). Nature 166: 949, 1950.

2. Paterson RR: Cordyceps: a traditional Chinese medicine and another fungal therapeutic biofactory? Phytochemistry 69: $1469-1495,2008$.

3. Kim HG, Shrestha B, Lim SY, et al: Cordycepin inhibits lipopolysaccharide-induced inflammation by the suppression of NF- $\mathrm{kB}$ through Akt and p38 inhibition in RAW 264.7 macrophage cells. Eur J Pharmacol 545: 192-199, 2006.

4. Yun Y, Han S, Lee S, Ko S, Lee C, Ha N and Kim K: Anti-diabetic effects of CCCA, CMESS, and cordycepin from Cordyceps militaris and the immune responses in streptozotocin-induced diabetic mice. Nat Prod Sci 9: 291-298, 2003.

5. Ahn YJ, Park SJ, Lee SG, Shin SC and Choi DH: Cordycepin: selective growth inhibitor derived from liquid culture of Cordyceps militaris against Clostridium spp. J Agric Food Chem 48: 2744-2748, 2000.

6. Sugar AM and McCaffrey RP: Antifungal activity of 3'-deoxyadenosine (cordycepin). Antimicrob Agents Chemother 42: 1424-1427, 1998

7. Müller WE, Weiler BE, Charubala R, et al: Cordycepin analogues of 2',5'-oligoadenylate inhibit human immunodeficiency virus infection via inhibition of reverse transcriptase. Biochemistry 30: 2027-2033, 1991.

8. Kodama EN, McCaffrey RP, Yusa K and Mitsuya H: Antileukemic activity and mechanism of action of cordycepin against terminal deoxynucleotidyl transferase-positive (TdT $\left.{ }^{+}\right)$ leukemic cells. Biochem Pharmacol 59: 273-281, 2000.

9. Cho MA, Lee DS, Kim MJ, Sung JM and Ham SS: Antimutagenicity and cytotoxicity of cordycepin isolated from Cordyceps militaris. Food Sci Biotechnol 12: 472-475, 2003.

10. Nakamura K, Konoha K, Yoshikawa N, Yamaguch Y, Kagota S, Shinozuka K and Kunitomo M: Effect of cordycepin (3'-deoxyadenosine) on hematogenic lung metastatic model mice. In Vivo 19: 137-141, 2005.

11. Nakamura K, Yoshikawa N, Yamaguchi Y, Kagota S, Shinozuka K and Kunitomo M: Antitumor effect of cordycepin (3'-deoxyadenosine) on mouse melanoma and lung carcinoma cells involves adenosine A3 receptor stimulation. Anticancer Res 26: 43-48, 2006.

12. Thomadaki H, Scorilas A, Tsiapalis CM and Havredaki M: The role of cordycepin in cancer treatment via induction or inhibition of apoptosis: implication of polyadenylation in a cell type specific manner. Cancer Chemother Pharmacol 61: 251-265, 2008.

13. Jeong JW, Jin CY, Park C, et al: Induction of apoptosis by cordycepin via reactive oxygen species generation in human leukemia cells. Toxicol In Vitro 25: 817-824, 2011.

14. Odunsi K and Old LJ: Tumor infiltrating lymphocytes: indicators of tumor-related immune responses. Cancer Immun 7: 3, 2007.

15. Zou W: Immunosuppressive networks in the tumour environment and their therapeutic relevance. Nat Rev Cancer 5: 263-274, 2005. 
16. Jeong MH, Seo MJ, Park JU, et al: Effect of cordycepin purified from Cordyceps militaris on Th1 and Th2 cytokines in mouse splenocytes. J Microbiol Biotechnol 22: 1161-1164, 2012.

17. Zou W: Regulatory T cells, tumour immunity and immunotherapy. Nat Rev Immunol 6: 295-307, 2006.

18. Curiel TJ: Regulatory T cells and treatment of cancer. Curr Opin Immunol 20: 241-246, 2008.

19. Liu Z, Kim JH, Falo LDJ and You Z: Tumor regulatory T cells potently abrogate antitumor immunity. J Immunol 182: 6160-6167, 2009.

20. Malmberg KJ: Effective immunotherapy against cancer: a question of overcoming immune suppression and immune escape? Cancer Immunol Immunother 53: 879-892, 2004.

21. Horowitz B, Goldfinger BA and Marmur J: Effect of cordycepin triphosphate on the nuclear DNA-dependent RNA polymerases and poly(A) polymerase from the yeast, Saccharomyces cerevisiae. Arch Biochem Biophys 172: 143-148, 1976.

22. Muller WE, Seibert G, Beyer R, Breter HJ, Maidhof A and Zahn RK: Effect of cordycepin on nucleic acid metabolism in L5178Y cells and on nucleic acid-synthesizing enzyme systems. Cancer Res 37: 3824-3833, 1977.

23. Rosenberg SA: Karnofsky Memorial Lecture. The immunotherapy and gene therapy of cancer. J Clin Oncol 10: 180-199, 1992.

24. von Boehmer H: Mechanisms of suppression by suppressor $\mathrm{T}$ cells. Nat Immunol 6: 338-344, 2005.

25. Itoh M, Takahashi T, Sakaguchi N, Kuniyasu Y, Shimizu J, Otsuka F and Sakaguchi S: Thymus and autoimmunity: production of $\mathrm{CD} 25^{+} \mathrm{CD}^{+}$naturally anergic and suppressive $\mathrm{T}$ cells as a key function of the thymus in maintaining immunologic selftolerance. J Immunol 162: 5317-5326, 1999.

26. Takahashi T, Kuniyasu Y, Toda M, et al: Immunologic selftolerance maintained by $\mathrm{CD} 25^{+} \mathrm{CD} 4^{+}$naturally anergic and suppressive $\mathrm{T}$ cells: induction of autoimmune disease by breaking their anergic/suppressive state. Int Immunol 10 : 1969-1980, 1998.
27. de la Rosa M, Rutz S, Dorninger H and Scheffold A: Interleukin-2 is essential for $\mathrm{CD} 25^{+} \mathrm{CD} 4^{+}$regulatory $\mathrm{T}$ cell function. Eur J Immunol 34: 2480-2488, 2004.

28. Furtado GC, Curotto de Lafaille MA, Kutchukhidze N and Lafaille JJ: Interleukin 2 signaling is required for $\mathrm{CD}^{+}{ }^{+}$regulatory T cell function. J Exp Med 196: 851-857, 2002.

29. Yao Z, Kanno Y, Kerenyi M, et al: Nonredundant roles for Stat5a/b in directly regulating Foxp3. Blood 109: 4368-4375, 2007.

30. Yamagiwa S, Gray JD, Hashimoto S and Horwitz DA: A role for TGF- $\beta$ in the generation and expansion of $\mathrm{CD} 4^{+} \mathrm{CD} 25^{+}$ regulatory $\mathrm{T}$ cells from human peripheral blood. J Immunol 166: 7282-7289, 2001.

31. Ghiringhelli F, Puig PE, Roux S, et al: Tumor cells convert immature myeloid dendritic cells into TGF- $\beta$-secreting cells inducing $\mathrm{CD} 4{ }^{+} \mathrm{CD} 25^{+}$regulatory $\mathrm{T}$ cell proliferation. J Exp Med 202: 919-929, 2005

32. Chen W, Jin W, Hardegen N, et al: Conversion of peripheral $\mathrm{CD} 4{ }^{+} \mathrm{CD} 25^{-}$naive $\mathrm{T}$ cells to $\mathrm{CD} 4{ }^{+} \mathrm{CD} 25^{+}$regulatory $\mathrm{T}$ cells by TGF- $\beta$ induction of transcription factor Foxp3. J Exp Med 198: 1875-1886, 2003.

33. Valérie D, Amit A, Hyoung K, et al: IL-4 inhibits TGF- $\beta$-induced Foxp $^{+}{ }^{+}$T cells and, together with TGF- $\beta$, generates IL- $9^{+}$IL- $10^{+}$ Foxp3-effector T cells. Nat Immunol 9: 1347-1355, 2008.

34. Xiaoyu $\mathrm{H}$ and Lionel BL: Cross-regulation of signaling pathway by interferon- $\gamma$ : implication for immune response and autoimmune diseases. Immunity 31: 539-550, 2009.

35. Chen ML, Pittet MJ, Gorelik L, et al: Regulatory T cells suppress tumor-specific CD8 T cell cytotoxicity through TGF- $\beta$ signals in vivo. Proc Natl Acad Sci 102: 419-424, 2005. 